\title{
Residents' Social Interactions in Market Square and Its Impact on Community Well-Being
}

\author{
*Dr. OLUWAGBEMIGA PAUL AGBOOLA", Dr. MOHD HISYAM RASIDI², Dr. ISMAIL BIN SAID³, \\ MA.SOLOMON DYACHIA ZAKKA ${ }^{4}$, MA.ABDUL-WAHAB SHUAIBU 5 \\ 1, 2,3Faculty of Built Environment, Department of Landscape Architecture, Universiti Teknologi Malaysia. Postcode 81310, Skudai, \\ Johor Bahru, Malaysia. \\ 4, 5 Faculty of Built Environment, Department of Urban and Regional Planning, Universiti Teknologi Malaysia. Postcode 81310, \\ Skudai, Johor Bahru, Malaysia \\ 'E mail: Agbofavour41@yahoo.com, 2E mail:hisyamrasidi@gmail.com³ ${ }^{2}$ mail: $\underline{\text { b-ismail@utm.my }}$ \\ 4E mail: zakkasolomon2008@yahoo.com,5E mail: abdulwahab.shuaibu@gmail.com
}

\begin{tabular}{l} 
A R T I C L E I N F O: \\
\hline Article history: \\
Received 28September 2017 \\
Accepted 8October 2017 \\
Available online 15 October \\
2017 \\
\hline Keywords: \\
Social interactions; \\
Ethnic groups, \\
Market square; \\
Well-being; \\
Nigeria.
\end{tabular}

This work is licensed under a Creative Commons Attribution - NonCommercial - NoDerivs 4.0. "CC-BY-NC-ND"

\begin{abstract}
A B S T R A C T
This study aims at ameliorating the associated challenges emanated from the ineffective planning, management and design of market square as well as appraisal of the interactions among people of diverse ethnicity. Hence, the study explores users' interactions and activities within three markets square in rural neighborhoods of South-west, Nigeria. The significant relationship between resident's interactions and the community well-being was explored. Consequently, this study highlights the influence of the market square as a typical neighborhood open space on residents' well-being. The study's quantitative approach encircled the purposive structured survey questionnaire data obtained from Yorubas, Hausas, and Ibos respondents $(n=382)$; and analyzed by SPSS statistical package (version 22). Meanwhile, the qualitative data included observation of various activity pattern among the three ethnic groups. The study's findings revealed that an improvement in the market square quality becomes necessary in order to increase residents' interactions and well-being. Also, the study elucidates the appropriate link between the built environment, residents' interactions, and well-being. It is concluded that residents' well-being is a reflection of an experience manifested within the interplay of individuals and groups' social interactions. This study of people and place relationships could better equip the professionals in the built environment on the importance of creating a sustainable open space towards improving residents' well-being and rural community revitalization efforts.
\end{abstract}

JOURNAL OF CONTEMPORARY URBAN AFFAIRS (2018) 2(2), 24-32.

https://doi.org/10.25034/ijcua.2018.3668

www.ijcua.com

Copyright (C) 2017 Journal Of Contemporary Urban Affairs. All rights reserved.

\section{Introduction}

A considerable amount of literature has reinstated the economic significance of markets in rural development through exchange and distribution of commodities and services (Vagale,

*Corresponding Author:

University of Technology, Malaysia

E-mail address: Agbofavour41@yahoo.com 
1972; Trager Lillian, 1979; Eben-Saleh and Alkalaf, 1999). Aside from the economic significance of markets, markets also encompass human social aspects. The social significance of market is exemplified by Omole, Lukman, \& Baki, (2013) in that market acts as a gathering point for the protraction of cultural lineage obligations and responsibilities. Thus, market square acts as a social arena, where social activities, like courtship, visiting friends, and exchange of ideas occur. Other social activities in market square include dancing, dating, and recreational events (Anthonia, 1973). Recently, researchers have shown an increased interest in the exploration of varying degree of social interactions among market Square's users and community residents of both developed and developing countries. However, little efforts have been initiated in exploring the social interactions among diverse ethnic groups in the market square (which is also known as Oja in Yoruba parlance) of such a large and multicultural nation as Nigeria. A host of challenges often time associated with the use of the traditional rural market square, which has been established as an important typical rural neighborhood open space in Nigeria. These challenges as reinstated by Agboola, Rasidi, \& Ismail (2016), include inadequate social interactions, contestation over the use, the need for improved facilities and amenities, security and environmental hazards amongst others. Meanwhile, the interactions among diverse ethnics within the markets are often threatened by indigene and settler's dichotomy and as such have negative impacts on the rural developments efforts.

Other constraints in people social interaction within the traditional rural market in Nigeria are traceable to improper developmental issues and inadequate facilities. For instance, the significance of social interaction attributed to non-availability and in some cases management of adequate market's facilities and amenities. Similarly, haphazard and uncoordinated physical planning has been a cog in the wheel of market's space utilization and management. A reflection of these could be seen from market's physical conditions traceable to poor accessibility, sanitary conveniences, inadequate water supply, electricity, and other community facilities. The planning challenges include encroachment on the market boundary, poor landscaping, inefficient refuse disposal system, and other services utilities (Uzuegbunam 2012).

This study aimed at proffering solution towards ameliorating the associated social interaction challenges in the market square. Establishing adequate social interactions among diverse market's users portray identifiable benefits. For instance, a well-equipped and planned market square will impact positively on the users' wellbeing and satisfaction. Other significance includes enhancement of peoples' togetherness and cordial relationship among the diverse ethnics. In this study's context, well-being is synonymous with a sense of community which refers to the feelings that community residents have towards each other. This depicts belongingness, shared loyalty and neighborliness (McMillan, David \& Chavis, 1986). In recent time, enhancement of human well-being remains a vital issue that required attention among professionals in built environment. In view of this, there is a desirous need for proper open spaces' planning targeting improvement on peoples' interactions and movement (Southworth \& Owens, 1993). It is evident that people's perception of social interaction has intertwined positively with residents' sense of community (Lund, 2002; Wood, Frank \& Giles-Corti, 2010).

For proper understanding and clarity, this research is underpinned by social interactions, cohesion and attachment concepts. These variables are paramount towards achieving the following: (i) creation of enabling an environment for passive social contact among the users (ii) appropriate space for residents' interactions and community cohesion (Fleming, Baum, \& Singer, 1985) and lastly (iii) residents' attachment to the market (Peters, Elands, \& Buijs, 2010). Succinctly, the concepts captured the collective values of the processes and attachments that existed between people and their environment, which leads to community well-being (Davidson \& Cotter, 1986 and Nasar \& Julian 1995). This research work focused on the level of interactions among the diverse markets' users and the ability to facilitate the residents' wellbeing. Past studies have established that both the social interaction, place attachment can promote well-being (Maloutas \& Pantelidou, 2004). Therefore, the creation of social interaction and well-being remain vital and should be regarded as an agent towards the enhancement of the built environment. Consequently, the affective bond between people and the environment in the rural community could further enhance social relationships, community experiences, and resident's well-being. This study's ethnics respondents are the Yoruba, Hausa, and lbos who are patrons and vendors within three different markets in South-west, Nigeria. Holistically, the research findings appraise the 
present condition of the market environments and the socio-cultural background of its users.

\section{Concepts of Social Interaction, Social Cohesion, and Well-Being}

Social interaction as coined as the associated communal contact between residents while involving in various daily activities (Hesham, Ismail \& Hisyam 2014). Past literature affirm that social interactions among diverse ethnic's groups promote participatory drives within the community and subsequently lead to a feeling of acceptance of each other's live (Putnam, 2000). Past studies have shown in clear terms that a relationship exists between the people's social interaction, well-being, and the physical environment. It is noteworthy to state that; the physical aspects of the environment can contribute to the improvement of social interactions leading to general community residents' well-being as conceptualized in Figure 1. A good social interaction involves adequate social network upon which social capital is rooted. While on the other hand, social capital responds to diverse interpersonal factors such as belongingness, the opportunity for social interaction, social network, norms and mutual trust among ethnic groups (Peters, Elands, \& Buijs, 2010).

Adequate interactions among ethnics are a panacea towards achieving social cohesion, between the individuals or groups (Potapchuk, Crocker \& Schechter, 1997; Marshall \& Stolle, 2004). It becomes evident that the associated significance of market square as a neighbourhood opens space relies on its affordance of human social contacts among diverse ethnics of cultural backgrounds (Lofland, 1998; Fainstein, 2005). The significance of interactions vested solely on the provision of reliefs perlatives from human daily struggles and tensions (Dines, \& Cattell, 2006). In addition, appropriate design and managements of open space often attract greater percentage of resident's visitation and subjective place for human interactions (Dines, \& Cattell, 2006; Uitermark, 2003). Similarly, open space such as market square could promote residents' satisfaction, dependence, and trust (Kim, 1997; Carmona, 2010). The higher the residential social interaction, the higher the community social development (Lalli, 1992).

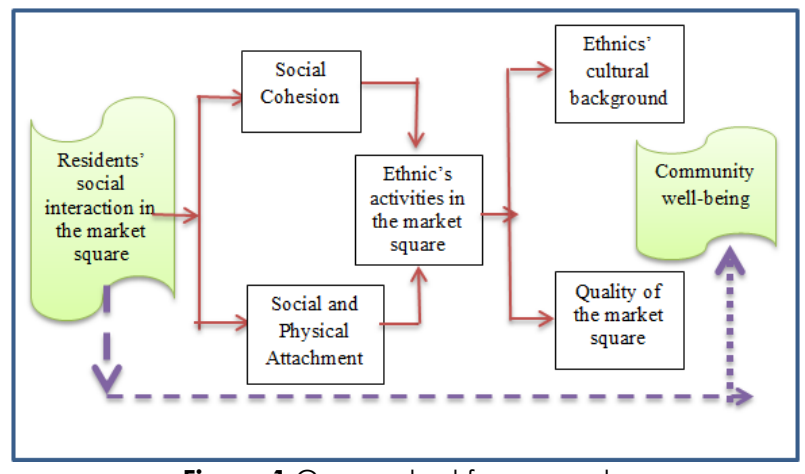

Figure 1.Conceptual frame work.

In another dimension, social interaction leads to neighbourliness and joint ownership prides. Neighbourliness involves a high level of friendly dispositions among residents, friends, and families, while it also promotes mutual respect, acceptance of diversities among ethnics' residents. Explicitly, neighbourliness is a relationship through which residents can communicate and share common ideas together. Pre- requisites for social bonding in market associates with people familiarity, regular use, and available facilities(Dines, \& Cattell, 2006). Well-being according to Chen, (2006) refers to the totality of all residents' encounters, relationships, and experiences that emanated from harmonious relationships. On the other hand, community well-being could be categorized as socioeconomic, emotional, health and safety (Kil, et. al., 2012). This study's definition of well-being is the existence of the humans' neighbourliness; interpersonal relationship and joint involvement in community programs as equally reinstated (Butterworth, 2000). The author opined that the determinants of community well-being include social ties, sense of community, community cohesion and sense of place. Community well-being included safe and accessible environment, as well as joint participation in community activities by ethnics' groups.

\section{Methodology: Quantitative and Qualitative Measurement of Items}

In a view to properly comprehend the research findings, measurement items of the quantitative questionnaire were rated on a "1-5" Likert scale, targeting the respondents' responses on sharing perceptions. The "5" statement indices elicited includes (i) Sharing market square with other ethnic's groups is always good (SHA1), (ii) Sharing market square with other ethnic's groups is always helpful (SHA2), (iii) Sharing market square with other ethnic's groups is always cherished by me (SHA3), (iv) Sharing market square with other ethnic's groups is always enjoyable (SHA4), (v) 
Sharing market square with other ethnic's groups brings mutual trust and understanding and gives me satisfaction (SHA5). The perception of the respondents on their well-being anytime they were in the market square was explored base on the following: (i) I am comfortable with the quality of the market anytime I found myself in the market square (QUA1), (ii) I am comfortable with the amenities and facilities provided in the market square (QUA2), (iii) I am comfortable with physical features of market square (QUA3), (iv) I am comfortable with the markets' security and safety (QUA4). Meanwhile, the "5-point" scale ranged from "Strongly agree" on "5" to "Strongly Disagree" on "1" with "Neither agree nor disagree" in the middle represented by " 3 ". Thus, "2" stand for "Disagree", while "4" for "Agree". For the interpretation, the mean value of " 3 " was considered to be the midpoint. Hence, the values below " 3 " were considered "uncomfortable" while a mean value above " 3 " was considered "comfortable".

For the qualitative observation, checklist used in the previous study of Mack, etal., (2005) was adopted. Rating of the observation was based on the 4-point scale while the observation was conducted at the market square of three different neighborhoods. The checklist reflected users' duration of interactions, with no interaction rated on "0" scale, short interaction (less than 15 minutes) was rated on "+1" scale. Medium interaction (between 15 minutes to 20 minutes) was rated on "+2" scale, and lastly, the long interaction (between 21 minutes to 30 minutes) was rated on "+3" scale.

\section{Case Study Areas}

As depicted in Figure 2, the position occupied by the case study neighbourhoods. ljebu-jesa, ljeda, and lloko towns are located under Oriade local government council, Osun State. ljeda-ljesa is located at latitude 70401 North and longitude 40 501 East while lloko is located at latitude $7^{\circ} 381$ North and longitude $4^{\circ} 4^{\prime}$ East. Meanwhile, ljebu-jesa town has latitude of 70.451 and longitude 40431 degree east. The three towns shared boundaries with Efon-Alaaye in Ekiti State, Eti-oni, Ilesha, Iwaraja, Iwoye, and Erinmo. The Figure 3 and 4 shows the sectional areas within the case study market. However, the markets have been in the existence for more than ten decades, serving as a socio-economic, cultural, religious and recreational environment for the teaming users.

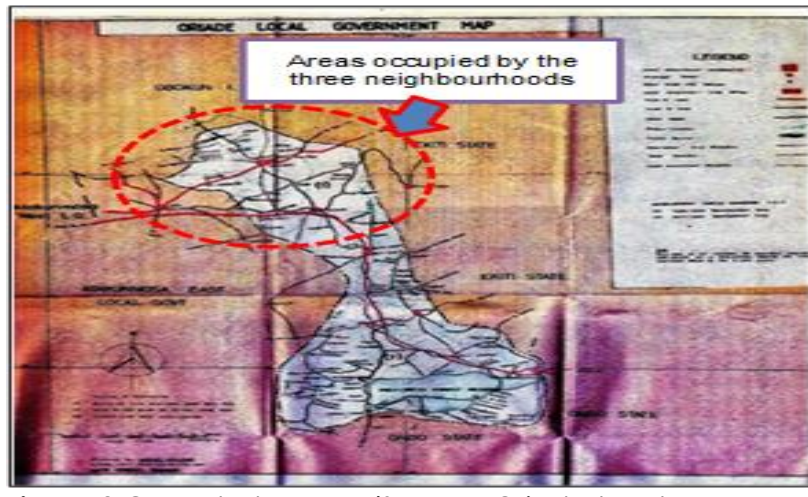

Figure 2.Case study map. (Source: Oriade local government local authority board)

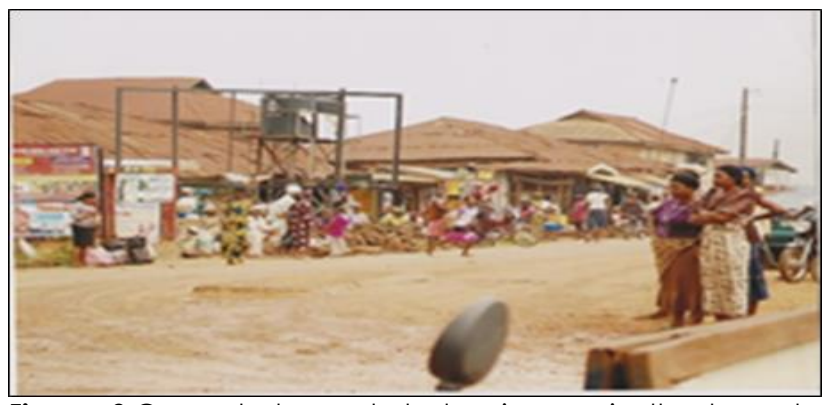

Figure 3.Case study market showing agricultural product display section. (Source: Field work, 2015)

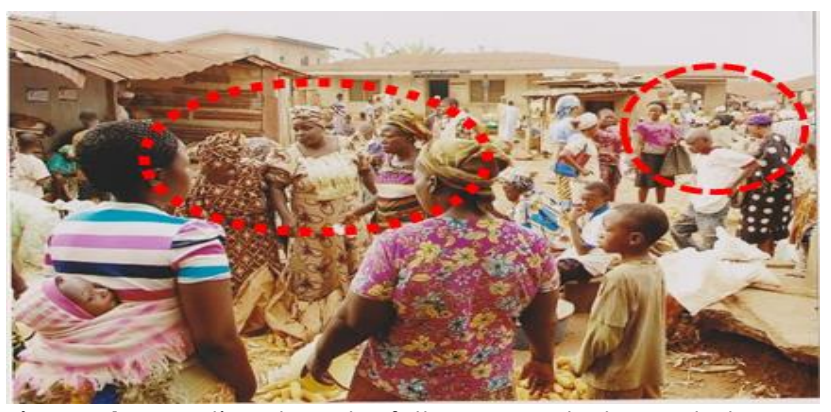

Figure 4.A sectional part of the case study market square showing diverse interactions among the users. (Source: Field work 2015)

\section{Results and Discussion}

A total number of 382 respondents of three neighbourhoods of ljebu-jesa, Iloko, and ljeda participated in the completion of the study's structured survey questionnaires. They were selected through stratified random sampling taking into account their age, sex, ethnics and length of residency. A total number of 187 (49\%) were males, while 195 (51\%) were females. As regards to the age distributions, 69 (18\%) of respondents' age falls between 12-18 years, 127 (33\%) having age ranged between 19 - 29 years, 105 (27 \%) were within the age bracket 30-59 years. Lastly, 81 (21\%) were aged 60 years and above. In response to the respondents' ethnic's background, 231 (60.5\%) of respondents were Yorubas, 96 (25\%) were Igbos, and 55 (14\%) were Hausas. Respondents from ljebu-jesa 
totaling 180 (42\%), ljeda had 84 (31\%), and lloko with 101 (25\%).

In connection to the respondents' perception of well-being, Table 1 shows mean value of 2.91 (SD 1.52) and 2.3 (SD 1.48), that signified that the respondents were not comfortable with the quality of the market's surroundings (QUA1) as well as with the amenities and facilities provided in the market square (QUA2). Likewise, a mean value of 2.7 (SD 1.72), and 2.62 (SD 1.73) were recorded for respondents' perception of physical features of market square (QUA3), and markets' security and safety (QUA4) respectively. The values fall below benchmark value of " 3 " which signaled respondents' uncomfortable dispositions.

Table 1. Quantitative Result from the descriptive analysis

\begin{tabular}{|c|c|c|c|c|c|c|c|c|c|c|c|c|c|}
\hline \multicolumn{12}{|c|}{ Responses from Likert scale } & \multicolumn{2}{|c|}{ Statistics } \\
\hline \multirow{4}{*}{$\begin{array}{l}\text { Item } \\
\text { codes }\end{array}$} & \multirow{4}{*}{$\begin{array}{l}\text { Strongly } \\
\text { agree }\end{array}$} & \multirow{4}{*}{ 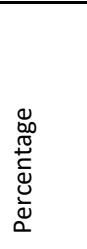 } & \multirow{4}{*}{ Agree } & \multirow{4}{*}{ 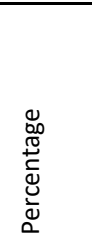 } & \multicolumn{4}{|l|}{ Neither } & \multirow{2}{*}{\multicolumn{2}{|c|}{ Strongly }} & \multirow{4}{*}{$\begin{array}{l}\text { Total } \\
\text { respondents }\end{array}$} & \multicolumn{2}{|c|}{ Average } \\
\hline & & & & & Agree & & Disagree & & & & & Mean & SD \\
\hline & & & & & & 空 & & $\stackrel{0}{\circ}$ & disagree & 密 & & score & \\
\hline & & & & & Disagree & 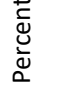 & & 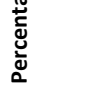 & & 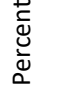 & & & \\
\hline SHA1 & 160 & 41.9 & 124 & 32.5 & 13 & 3.40 & 43 & 11.30 & 42 & 11.0 & 382 & 3.80 & 1.36 \\
\hline SHA2 & 184 & 48.2 & 110 & 28.8 & 09 & 2.4 & 44 & 11.50 & 35 & 9.20 & 382 & 3.90 & 1.33 \\
\hline SHA3 & 174 & 45.5 & 119 & 31.1 & 05 & 1.30 & 61 & 15.90 & 23 & 6.02 & 382 & 3.52 & 1.48 \\
\hline SHA4 & 184 & 48.2 & 110 & 28.8 & 07 & 1.80 & 39 & 10.20 & 42 & 11.0 & 382 & 3.90 & 1.37 \\
\hline SHA5 & 171 & 44.8 & 82 & 21.5 & 11 & 2.9 & 10 & 2.60 & 108 & 28.3 & 382 & 3.50 & 1.70 \\
\hline QUA1 & 68 & 17.8 & 93 & 24.3 & 13 & 3.40 & 79 & 20.70 & 129 & 33.8 & 382 & 2.91 & 1.52 \\
\hline QUA2 & 52 & 13.6 & 64 & 16.8 & 20 & 5.20 & 94 & 24.60 & 152 & 39.8 & 382 & 2.30 & 1.48 \\
\hline QUA3 & 98 & 25.7 & 70 & 18.3 & 14 & 3.70 & 34 & 8.90 & 166 & 43.5 & 382 & 2.70 & 1.72 \\
\hline QUA4 & 102 & 26.7 & 51 & 13.4 & 05 & 1.30 & 53 & 13.90 & 171 & 44.8 & 382 & 2.62 & 1.73 \\
\hline
\end{tabular}

The result from Table 1 revealed that the generality of the residents unanimously agreed that a very comfortable markets' status has not been attained. The results, therefore, suggest that improvements become necessary on the general condition and quality of the market. This becomes necessary in efforts to attain an ideal market standard that could be worthy of impacting positively on the residents' community well-being. Places that could be perceived beneficial to the residents' well-being must equally possess the basic standard requirements that could promote a very comfortable environment for the teaming users. In response to respondents' perception of social interaction, results indicated a mean value of 3.8 (SD 1.36) and 3.9 (SD 1.33) were exhibited for SHAl and SHA2. In the same manner, the mean value of 3.52 (1.48), as well as 3.9 (SD 1.37), showcased the respondents' perception on SHA3 and SHA4 accordingly.

Lastly was the respondents' perception of sharing a market square with other ethnic's groups. The result of respondents' perception on sharing market brings mutual trust and understanding and gives satisfaction (SHA5) exhibited an average mean value of 3.50 (SD 1.70). Overall, the mean values exceeded the benchmark of "3", which affirmed a positive emotional connection towards residents' sharing the market with others. Despite the challenges associated with the qualities of the market, residents still consider it worthy to interact and integrate. This result affirmed the significance of the market in the lives of its users, as corroborated by the past market study of Dines, \& Cattell, (2006) and Nasution \& Zahrah (2014). Thus, improvements in the quality of the market surroundings could as well enhance the high level of interaction among the users. In view of this, urban designers are encouraged to achieve the strategic sustainable planning for long-term vision. This is considered as the important indicators to achieve the high level of human life and users' satisfaction (Nikoofam \& Mobaraki, 2016).

For the quantitative analysis, a total number of 50 participants' observations were carried out within the three markets square. The qualitative observation results in Anthonia, (1973); Agboola, Rasidi, \& Ismail (2016); Uzuegbunam, (2012); and 
McMillan, David \& Chavis, (1986) show the diverse interactions among the Yoruba, Hausa, and lbo within the 3 major markets square in the area. The findings of quantitative result validate the quantitative result that established a fair sharing of the market among the ethnics.

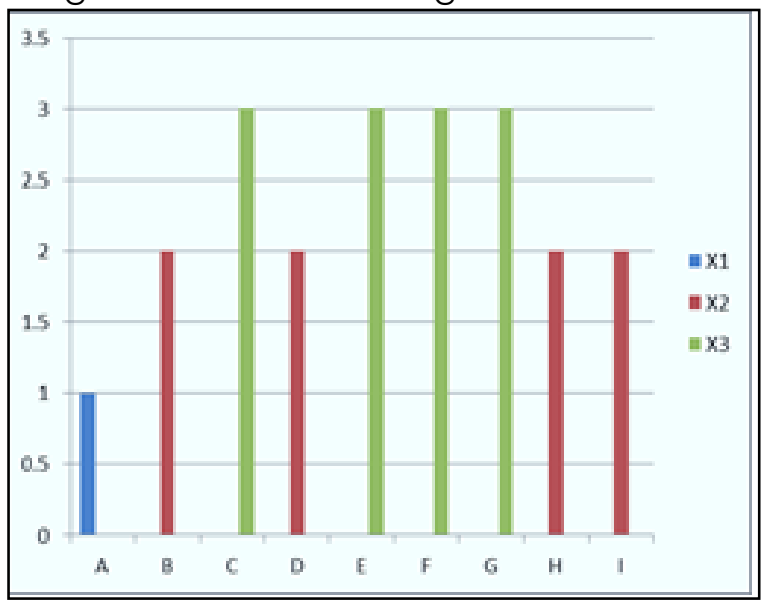

Figure 5.Residents' Interaction and duration in ljebu-jesa market place. $\mathbf{A}=$ Hausa \& Igbo, $\mathbf{B}=$ Hausa \& Yoruba, $\mathbf{C}=$ Hausa \& Hausa, $\mathbf{D}=$ Yoruba \& Igbo, $\mathbf{E}=$ Yoruba \& Hausa, $\mathbf{F}=$ Yoruba \& Yoruba, $\mathbf{G}=$ lgbo \& Hausa, $\mathbf{H}=$ lgbo \& Yoruba, $\mathbf{I}=$ lgbo \& Igbo. $\times 1=$ Less than 15 minutes (short interaction), $\times 2=$ between 15 to 20 minutes (medium interaction), $\times \mathbf{3}=$ between 20 to 30 minutes (long interaction)

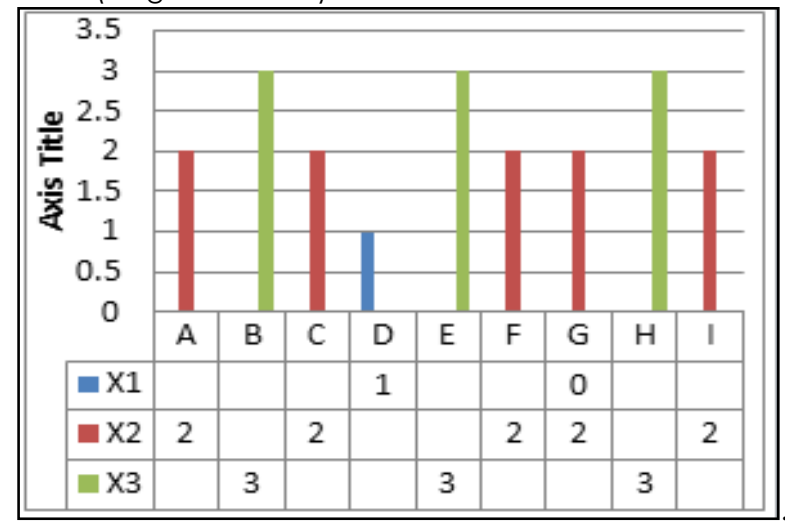

Figure 6.Residents'Interaction and duration in lloko township market place. $\mathbf{A}=$ Hausa \& Igbo, $\mathbf{B}=$ Hausa \& Yoruba, $\mathbf{C}=$ Hausa \& Hausa, $\mathbf{D}=$ Yoruba \& Igbo, $\mathbf{E}=$ Yoruba \& Hausa, $\mathbf{F}=$ Yoruba \& Yoruba, $\mathbf{G}=$ lgbo \& Hausa, $\mathbf{H = l g b o} \&$ Yoruba, I=lgbo \& Igbo. $\times \mathbf{1}=$ Less than 15 minutes (short interaction), $\times \mathbf{2}=$ between 15 to 20 minutes (medium interaction), $\times \mathbf{3}=$ between 20 to 30 minutes (long interaction)

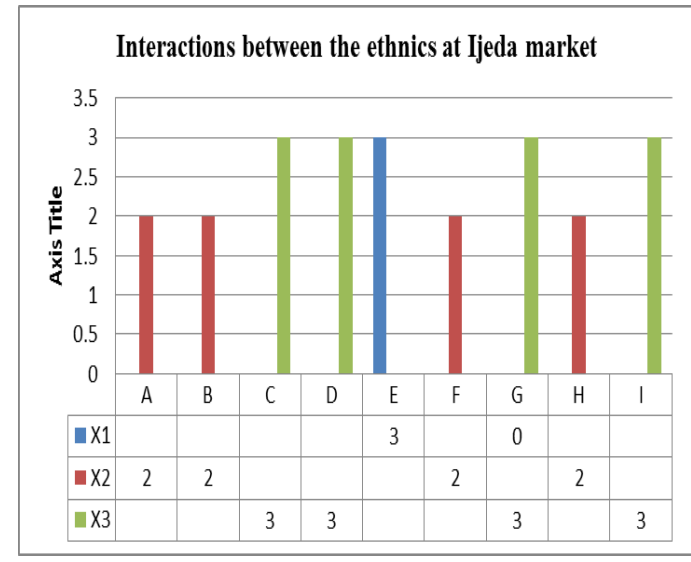

Figure 7.Residents' interaction and duration in ljeda market place. $\mathbf{A}=$ Hausa \& Igbo, $\mathbf{B}=$ Hausa \& Yoruba, $\mathbf{C}=$ Hausa \& Hausa, $\mathbf{D}=$ Yoruba \& Igbo, $\mathbf{E}=$ Yoruba \& Hausa, $\mathbf{F}=$ Yoruba \& Yoruba, $\mathbf{G}=$ lgbo \& Hausa, $\mathbf{H}=$ lgbo \& Yoruba, $\mathbf{I}=$ lgbo \& Igbo. $\times \mathbf{1}=$ Less than 15 minutes (short interaction), $\times \mathbf{2}=$ between 15 to 20 minutes (medium interaction), $\times \mathbf{3}=$ between 20 to 30 minutes (Long interaction)

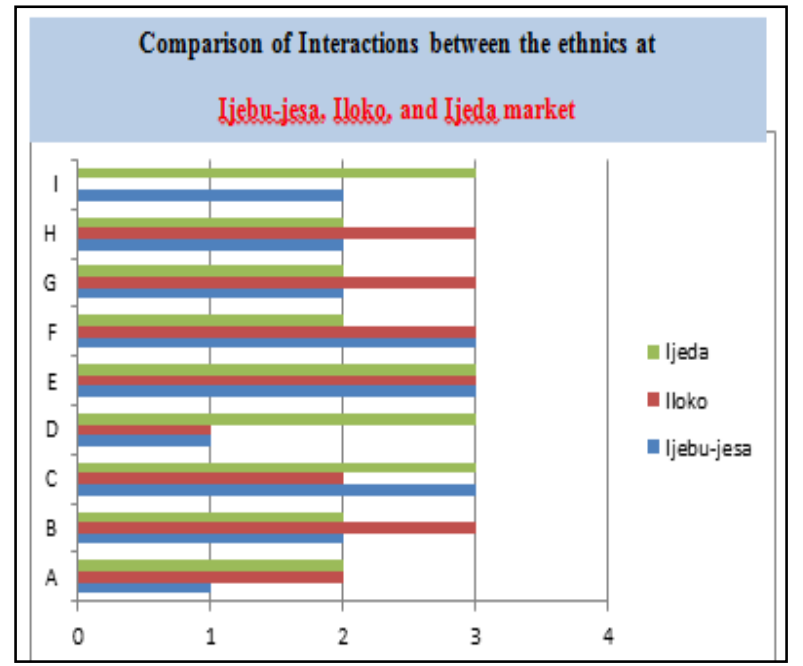

Figure 8.Comparison of residents' interaction and duration in the three-neighbourhood market place. A=Hausa \& Igbo, $\mathbf{B}=$ Hausa \& Yoruba, $\mathbf{C}=$ Hausa \& Hausa, $\mathbf{D}=$ Yoruba \& Igbo, $\mathbf{E}=$ Yoruba \& Hausa, $\mathbf{F}=$ Yoruba \& Yoruba, $\mathbf{G}=$ lgbo \& Hausa, $\mathbf{H}=$ Igbo \& Yoruba, $\mathbf{I}=$ Igbo \& Igbo. $\times \mathbf{l}=$ Less than 15 minutes (short interaction), $\times \mathbf{2}=$ between 15 to 20 minutes (medium interaction), $\times 3=$ between 21 to 30 minutes (long interaction)

From Figure 5, it could be deduced that long interaction (20-30 minutes) was observed between Yoruba and Hausa, Igbo and Hausa in ljebu-jesa market. Meanwhile, medium interaction (15-20 minutes) was established between Igbo and Yoruba. However, Figure 6, depicted the long interaction between the three ethnics at lloko market, while short interaction (less than 15 minutes) only occurred between Yoruba and Igbos. The third observation in ljeda market was shown in Figure 7, in which it revealed that short interaction (less than 15 minutes) existed between Yoruba and Hausa within the market. This was traceable to the greetings and charting as the purpose of 
interaction. Meanwhile, the long interactions that existed among the ethnics were as a result of the diverse purpose of interactions such as trading, religious and cultural activities and social activities (playing games, deliberations etc). The comparison of the interaction among the ethnics in the three markets was presented in Figure 8.

An interaction existed among the three ethnics, while the purpose of interactions was traceable to different activities ranging from greetings, religion, and social discussion and economic. Long and short interactions occurred between the three ethnics groups, which demonstrated that in spite of the various challenges and iota of conflict, engaging in some activities such as trading, social-cultural activities build social interaction among the groups. An indication that markets' environment should be designed in a bid to facilitate various activities and joint participation. This target at meeting the needs, preferences, and intention of users (Carr, 1982). Similarly, peoples' sense of empathy and understanding plays a significant role in the interactions (Forouzande \& Motaliebi, 2012).

Similarly, users' willingness to share the market with each other indicates encouragements for social interaction and sense of solidarity amongst them (Perkins, et al., 1996). Hence, meaningful encounters in market squares have a positive impact on the sustenance of residents' wellbeing as supported by (Dines, \& Cattell, 2006). Also, social encounters among people create a sense of belonging, integration, and neighbourhood attachment. This was corroborated by the previous studies of Mutiara \& Isami, 2012 and Ibrahim, Omar \& Mohamad, 2013). The finding affirmed that the affordance of opportunities for social interaction in the market square would promote human needs which are essential to the psychological development of individuals and community sustainability (Berkowitz, 1996 and Agboola, Zango \& Zakka, 2015). Likewise, the residents' urge to use the market square encourages being parts of the community and helps to develop and promoting residents' well-being, self-identity and communal activities ( Bryne \& Wolch, 2009 and Agboola, Rasidi \& Said, 2015).

\section{Conclusion and Recommendation}

This paper focused on the people-place relationship, and thus established that public open space such as market square offers an opportunity for diverse ethnic's relationship despite the likelihood of conflict and rifts among users. This current study contributes substantially to the general understanding that the social interactions that take place among the ethnic groups in the market square. The findings would not only give sustenance to peoples' shared values but would also influence their well-being within the community. A good neighbourhood environment comprising market square as an integral part is noted to facilitate communal contact, well-being, and environmental sustainability when properly landscaped and equipped (Ahianba, Dimunna \& Okogun, 2008 and Agboola, 2011).

In line with the aforementioned, this study suggests that in the quest of improving interethnic relations and understanding, appropriate machinery should be put in place towards improving the role played by the markets' square. A well-equipped, landscaped, functional and conducive market will improve people's positive perception and invariably contributes to peoples' decision to remain in the specific area. Also, the establishment of a well-planned market would encourage peoples' participation in a diverse range of activities. Therefore, provision of facilities, features, amenities, landscape features, and general maintenance becomes essential and every potential opportunity should be harnessed. As a result, adequate attention is needed towards improving the rural market square in Nigeria.

\section{Acknowledgment}

Authors express gratitude to the research assistants that helped during the data collection and the participants' field observation periods. Appreciations to the participants in Figure 4 for consented to authors' request to include their pictures in this article.

\section{References}

Anthonia, Q.B.O. (1973). The traditional marketing organization for smoked fish in the Yelwa Area of the Kanji Lake Basin in Kanji, a Nigerian Man-Made Lake", in Mabogunje, A.L(Ed) Vol. 2(1), 71-89. http://www.fao.org/docrep/005/AC876B/AC876B0 4.htm

Agboola O.P., Rasidi, M.H. \& Ismail S. (2016). Challenges in Sharing Neighbourhood Open Space among Residents in South-west, Nigeria. International Journal of Multidisciplinary Academic $\begin{array}{llll}\text { Research } & 4 & \text { (2). }\end{array}$ https://www.researchgate.net/publication/306106 944_CHALLENGES_IN_SHARING_NEIGHBOURHOOD_ OPEN SPACE AMONG RESIDENTS IN SOUTHWEST_NIGERIA

Agboola O.P.; Rasidi M. H.; \& Said I. (2015). Neighbourhood Open space as Cultural Heritage Value in Multi-ethnic Community of South-West Nigeria". Asian Journal of Humanities and Social 
Studies (ISSN: 2321 - 2799) Volume 03, Issue 01, 3850.

https://ajouronline.com/index.php/AJHSS/article/vi ew/2084

Agboola, O.P., Zango M. S.\& Zakka S. D. (2015). Towards Sustainability of Open Space's Planning and Management in Nigeria: Roles of Science and Technology". Jurnal Teknologi. Vol.27, No 14. 51-56. https://doi.org/10.11113/jt.v77.6446

Agboola O. P. (2011). Landscaping as a Catalyst to a Sustainable Healthy Environment. Global Journal of Researches in Engineering, Electrical and Electronics Engineering. Vol. 2, Issues 5 version 1.0. Pp1-8.http.//.www.globaljournals.org/GJREVOLIII/1

Ahianba,J.E, Dimunna,K.O., and Okogun,G.R.A (2008). Built Environment Decay and Urban Health in Nigeria. Human Ecology, 23(3), 259-265.

Berkowitz, B. (1996). Personal and community sustainability. American Journal of Community Psychology 24, 441-459. https://doi.org/10.1080/09709274.2008.11906079

Bryne, J. \& Wolch, J. (2009). Nature, Race, and Parks: Past Research And Future Directions For Geographic Research. Progress in Human Geography, 33 (6). 743-765. https://doi.org/10.1177/0309132509103156

Butterworth I. (2000). The Relationship between the Built Environment and Wellbeing: A literature review. Prepared for the Victorian Health Promotion Foundation. Melbourne, Australia. https://www.researchgate.net/publication/253984 800 The Relationship Between the Built Environm ent_and_Wellbeing_a_Literature_Review

Carmona, M. (2010). Contemporary Public Space: Critique and Classification, Part One: Critique Contemporary Public Space: Critique and Classification. Journal of Urban Design, 15 (1), 3741. https://doi.org/10.1080/13574800903435651

Carr, S. (1982). Some criteria for environmental form. In S. Kaplan \& R. Kaplan. The Relationship between the Built Environment and Wellbeing: a literature reviews (Eds.). Humanscape: Environments for people (pp. 156-160). Ann Arbor, USA: Ulrich's Books.

http://hiaconnect.edu.au/old/files/Built_Environme nt \%26 Wellbeing.pdf

Chen, D. (2006) Shared Outdoor Spaces, And Community Life: Assessing the Relationship between Design and Social InteractionMaster's Thesis, University of Guelph (Canada). https://scholarworks.sjsu.edu/cgi/viewcontent.cgi? article $=1340 \&$ context $=$ etd__projects

Davidson, W., \& Cotter, P. (1986). Measurement of a sense of community within the sphere of the city. Journal of Applied Social Psychology, 16(7), 608619. 1816.1986.tb01162.x

Dines, N., Cattell, V. (2006). Public Spaces, Social Relations and Well-being. The Policy Press,
Bristol.https://www.researchgate.net/publication/2 36574391 Public spaces social relations and well being in East_London

Eben-Saleh, M.A. "Alkalaf (1999). The Evolution of the Urban Built Form of Traditional Settlement in South Western Saudi - Arabia", International Journal of Building Science and its Application. 34 (6), 549669. https://doi.org/10.1016/s0360-1323(98)00047-x Fainstein, S.S. (2005). Cities, and diversity. Urban Affairs Review, 41(1), 3-19. https://doi.org/10.1177/1078087405278968

Fleming, R., Baum, A., \& Singer, J.F. (1985). Social Support and the Physical Environment. In S. Cohen and L. S. Syme (Eds.), Social Support and Health. 327-344. Orlando: Academic Press. http://www.mentalhealthpromotion.net/resources/ the-built-environment-and-mental-health.pdf

Forouzande A. J. \& Motaliebi G. (2012). The Role of Open Spaces in Neighborhood Attachment. International Journal of Architecture and Urban Development, 1(3). 11-20. http://ijaud.srbiau.ac.ir/article_54.html

Hesham E.O., Ismail S. \& Hisyam M. (2014). Residents' Perception Towards Social Interaction Among Malaysian Ethnic Groups in Urban Park. Recent Trends in Social and Behavior Sciences. 9-15. http://dx.doi.org/10.1201/b16658-4

Ibrahim F. I., Omar D. B. and Mohamad N. H. (2013). Quantitative Measures of Human Interaction in Open Spaces. Proceedings of the 1st International Conference on Research Methodology for Built Environment and Engineering. 17-18th December. (2013).

https://www.academia.edu/5426904/Quantitative _Measures_Of_Human_Interaction_in_Open_Space s

Kil, N., Stein, T. V, Holland, S. M., \& Anderson, D. H. (2012) Understanding Place Meanings In Planning And Managing The Wildland-Urban Interface: The Case Of Florida Trail Hikers. Landscape and Urban Planning, 107(4), .370-379. https://doi.org/10.1016/j.landurbplan.2012.07.004

Kim, W. (1997). Effects Of Dwelling Floor Level On Factors Related To Residential Satisfaction And Home Environment In High-Rise Apartment Buildings. Texas A. \& M., College station. https://www.semanticscholar.org/paper/TheConsequences-of-Living-in-High-Rise-BuildingsGifford/6bbla7af32de3cb880192db3734601710ca $\underline{\mathrm{fba0}}$

Lalli, M. (1992). Urban-Related Identity: Theory, Measurement, and Empirical Findings. Environmental Psychology, 12(4), 285-303. https://doi.org/10.1016/s0272-4944(05)80078-7

Lofland, L.H. (1998). The Public Realm: Exploring the City's Quintessential Social Territory. Aldine de Gruyter, New York, NY. https://academic.oup.com/sf/articleabstract/78/1/408/2234387? redirectedFrom=fulltext 
Lund, H. (2002). Pedestrian environments and sense of community. Journal of Planning Education and Research, 21 301-312. https://doi.org/10.1177/0739456x0202100307

Mack, N., Woodsong, C., MacQueen, K., Guest, G., \& Namey, E. (2005). Qualitative Research Methods: A Data Collector's Field Guide. NC: Research Triangle Park, Family Health International. https://www.fhi360.org/sites/default/files/media/do cuments/Qualitative\%20Research\%20Methods\%20\%20A\%20Data\%20Collector\%27s\%20Field\%20Guide. pdf

Maloutas, T., Pantelidou, M. (2004). Debates, and Developments: The Glass Menagerie Of Urban Governance And Social Cohesion: Concepts And Stakes/Concepts As Stakes. International Journal of Urban Regional Research 28(2), 449465.https://doi.org/10.1111//.03091317.2004.00528.x

Marshall, M., Stolle, D. (2004). Race and the City. Neighbourhood Context and the Development of Generalized Trust. Political Behaviour, 26, 125-154 https://doi.org/10.1023/B:POBE.0000035960.73204.6 $\underline{4}$

McMillan, David W. \& David M. Chavis. (1986), the sense of community: A definition and theory. Journal of Community Psychology 14(1).6-23. https://doi.org/10.1002/1520-

6629(198601)14:1<6::AIDJCOP2290140103>3.0.CO:2-1

Mutiara, S., \& Isami, K. (2012). Characteristic of Public Small Park Usage in Asia Pacific Countries: Case Study in Jakarta and Yokohama City.35. 412-419. https://doi.org/10.1016/j.sbspro.2012.02.106

Nikoofam, M., \& Mobaraki, A. (2016). In Pursuit of Sustainable Strategic Long-term Planning Throughout Meta-postmodernism as New Perspective of Stylistic Design. Contemporary Urban Affairs (JCUA), 1(1), 45-55. Doi: 10.25034/1761.1 (1) 45-55. https://doi.org/10.25034/1761.1(1)45-55

Omole, F. K., Lukman, Y., \& Baki, A. I. (2013). Analysis of Market Typology and Functions In The Development Of Osun State, Nigeria. International Journal of Development and Sustainability, 3(1), 55-69. https://www.isdsnet.com/ijds-v3n1-4.pdf

Peters, K., Elands, B., \& Buijs, A. (2010). Social Interactions In Urban Parks: Stimulating Social Cohesion?. Urban Forestry \& Urban Greening, 9, 93-100. https://doi.org/10.1016/j.ufug.2009.11.003

Perkins, D. D., Brown, B. B., \& Taylor, R. B. (1996). The ecology of empowerment: Predicting participation in community organizations. Journal of Social Issues, 52(1), 85-110.https://doi.org/10.1111/j.15404560.1996.tb01363.x

Putnam, R., (2000) In: Bowling Alone: The Collapse and Revival of American Community. Simon and Schuster, New York, NY. https://www.amazon.com/Bowling-AloneCollapse-American-Community/dp/0743203046
Potapchuk, W.R., Crocker, J.P., Schechter, W.H., (1997). Building community with social capital; chits and chums or chats with change. National Civic Review, 86(2), 129-139. https://doi.org/10.1002/ncr.4100860206

Nasar, J. L., \& Julian, D. A. (1995). The psychological sense of community in the neighborhood. Journal of the American Planning Association, 61(2), 178184.https://doi.org/10.1080/01944369508975631

Nasution A. D. and Zahrah W. (2014). Community Perception on Public Open Space and Quality of Life in Medan, Indonesia. Procedia - Social and Behavioral Sciences. $153 . \quad 585$ - 594. https://doi.org/10.1016/j.sbspro.2014.10.091

Southworth, M., \& Owens, P. (1993). The evolving metropolis: Studies of community, neighbourhood and street form at the urban edge. Journal of the American Planning Association, 59, 271-287. https://doi.org/10.1080/01944369308975880

Trager-Lillian (1979). Market Centres as Small Urban Places in Western Nigeria Small Urban Centres in Rural Development in Africa, African Studies Program, University of Wisconsin - Madison. I38-157. https://www.cambridge.org/core/journals/africanstudies-review/article/rural-urban-linkages-the-roleof-small-urban-centers-in-

nigeria/ABBAA134EBF201FOAOBC8B95C127E229

Uitermark J. (2003). 'Social Mixing' and the Management of Disadvantaged Neighbourhoods: The Dutch Policy of Urban Restructuring Revisited. Urban Studies, 40, (3), 531-549. https://doi.org/10.1080/0042098032000053905

Uzuegbunam Francis Onyechi (2012). Sustainable Development for Traditional Market-Places in South-Eastern Nigeria; A Case Study of NkwoOzuluogu Market Oraifite, Anambra state, Nigeria. Journal of Environmental Management and Safety. Vol.3, No.1. 139-158. http://www.cepajournal.com/index.php?option=c om_docman\&task=cat_view\&gid=40\&ltemid=87

Vagale, L. F. (1972). Traditional Markets in Nigeria: Focus on Ibadan City. The Polytechnic, Ibadan. Department of Town and Regional Planning, Ibadan, Nigeria, Periodic paper. https://books.google.com.tr/books/about/Anatom y_of_Traditional_Markets_in_Nigeri.htmleid=hg_UAA AAMAAJ\&redir esc $=y$

Wood, L., Frank, L. D., \& Giles-Corti, B. (2010). Sense of community and its relationship with walking and neighborhood design. Social Science \& Medicine, 70 , $1381-$ 1390.https://doi.org/10.1016/j.socscimed.2010.01.02 1 